\title{
Les Mégalithes du Larzac Aveyronnais
}

\section{Rémi Azémar}

URL : http://journals.openedition.org/adlfi/17236

ISSN : 2114-0502

Éditeur

Ministère de la culture

Référence électronique

Rémi Azémar, "Les Mégalithes du Larzac Aveyronnais », ADLFI. Archéologie de la France - Informations [En ligne], Midi-Pyrénées, mis en ligne le 03 mai 2016, consulté le 01 mai 2019. URL : http:// journals.openedition.org/adlfi/17236

Ce document a été généré automatiquement le 1 mai 2019.

(c) Ministère de la Culture et de la Communication, CNRS 


\title{
Les Mégalithes du Larzac Aveyronnais
}

\author{
Rémi Azémar
}

Lien Atlas (MCC) :

1 Dans le prolongement des programmes de recherche entamés sur le Larzac il y a près de trois décennies, l'inventaire des mégalithes dans cette partie de l'Aveyron se poursuit autour d'un capital dont la prospection systématique de terrain ne cesse de révéler la richesse, la variété et les potentialités pour une meilleure compréhension du mégalithisme des Grands Causses. Cette prospection inventaire, au-delà des problématiques de recherche qu'elle alimente, est aussi destinée à identifier un patrimoine menacé par les difficultés de protection face aux impacts des dynamiques humaines actuelles sur le milieu caussenard.

2 Sur la base des motifs précédents et pour l'apport scientifique, la connaissance du terrain permet d'accroitre de façon conséquente le nombre de monuments mégalithiques connus dans des proportions parfois étonnantes. L'exercice consiste en une localisation GPS et une couverture photographique complétées par les normes de relevé au $1 / 20^{\circ}$ et au $1 / 100$ ${ }^{e}$ de l'inventaire des mégalithes de France, dans la perspective d'une publication de synthèse.

3 De surcroît, chaque monument au-delà des informations déjà établies fait l'objet d'une fiche descriptive comprenant les informations pour les mesures ainsi que l'évaluation de l'état de conservation pour les matériaux, les traces de dégradations et les risques de menaces potentielles. L'objectif est de constituer un fichier-corpus à destination de tous les acteurs à même d'intervenir sur l'espace étudié et de les impliquer dans la protection de ce patrimoine pour les informer des mesures conservatoires déjà prises, de l'intérêt archéologique et des situations de menaces. En effet chaque année, et tout particulièrement pour le département de l'Aveyron, des destructions sont constatées avec, pour causes principales, l'absence de coordination entre les acteurs, les institutions et la méconnaissance des monuments, la malveillance étant finalement assez marginale 
dans les dégâts; la clé majeure de la solution paraît bien être dans une mise en réseau effective de tous les acteurs potentiels. Ainsi, autour du Service Régional de l'Archéologie et des chercheurs pour le Larzac aveyronnais, les liens suivis avec le Parc Régional des Grands Causses, les services des collectivités territoriales et tout particulièrement les intercommunalités, les services départementaux, la chambre d'Agriculture, les agriculteurs et surtout les nouveaux installés qui découvrent leur territoire, l'office National des Forêts, la Société civile des Terres du Larzac par exemple, les établissements de formation professionnelle agricole, les structures académiques de l'Education nationale, etc... peuvent constituer les ingrédients d'un dispositif efficace. Ainsi la législation pourrait être mieux connue et respectée, avec des systèmes de veille réactifs, la protection mieux assurée par les acteurs qui agissent sur cet espace, plus conscients de l'intérêt culturel et économique d'un patrimoine régional exceptionnel. La question d'urgence est celle de la protection; c'est la plus complexe face à des évolutions massives comme par exemple la fermeture des paysages caussenards liée à la modification des systèmes de production laitière du Roquefort et de parcours des troupeaux qui se traduit par la densification de la lande à buis et l'envahissement des pins sylvestres.

4 Sans aborder dans sa globalité la problématique de la protection des mégalithes caussenards, les opérations de valorisation resteront anecdotiques, avec le risque de masquer une érosion inéluctable de ce patrimoine, c'est là une des finalités essentielles de cette prospection inventaire.

\section{INDEX}

Index chronologique : Néolithique

Index géographique : Midi-Pyrénées, Aveyron (12)

operation Prospection inventaire (PI)

Mots-clés : mégalithe

\section{AUTEURS}

RÉMI AZÉMAR

BEN 